\title{
Effect of various hexoses on sperm capacitation and penetration of rat eggs in vitro
}

\author{
K. Niwa and A. Iritani \\ Department of Animal Science, College of Agriculture, Kyoto University, \\ Kyoto 606, Japan
}

\begin{abstract}
Summary. Fertilization of rat eggs in vitro could not be achieved when epididymal spermatozoa were preincubated and eggs in clots incubated in a chemically defined medium without D-glucose. Very high proportions (84-100\%) of eggs examined were undergoing fertilization when $2 \cdot 78-8 \cdot 34 \mathrm{mM}-\mathrm{D}$-glucose were included in the medium. The substitution of D-fructose or D-galactose for D-glucose resulted in very poor penetration rates $(0-4 \%)$, but D-mannose was effective for fertilization $(59-99 \%$ penetration). Incubations for sperm capacitation and egg fertilization in different media containing the various hexoses showed that rat epididymal spermatozoa could be partly capacitated without hexose, that D-glucose, D-mannose or D-galactose but not D-fructose is effective for sperm capacitation and that only D-glucose and D-mannose supported penetration of eggs in vitro.
\end{abstract}

\section{Introduction}

Fructose is known to be the major hexose in the semen of many mammalian species (Mann, 1964), but glucose is the hexose which is used as one of the energy sources for sperm capacitation and fertilization in vitro of mammalian eggs in a chemically defined medium. Lactate, pyruvate and glucose are all important medium components for in-vitro fertilization of eggs in the mouse (Miyamoto \& Chang, 1973) and the rat (Tsunoda \& Chang, 1975). Hoppe (1976) has shown that lactate is unnecessary and glucose is the major source of energy for capacitation of mouse epididymal spermatozoa and that the substitution of fructose for glucose results in very low fertilization rates. The purpose of the present study was to determine the effects of the different levels of glucose, and of various kinds of hexoses, on capacitation of spermatozoa and on penetration of rat eggs in vitro.

\section{Materials and Methods}

The basic medium was the modified Krebs-Ringer bicarbonate solution ( $94.6 \mathrm{~mm}-\mathrm{NaCl}, 4.78 \mathrm{~mm}-$ $\mathrm{KCl}, 1.71 \mathrm{~mm}-\mathrm{CaCl}_{2}, 1.19 \mathrm{~mm}-\mathrm{KH}_{2} \mathrm{PO}_{4}, 1.19 \mathrm{~mm}-\mathrm{MgSO}_{4}, 25.07 \mathrm{~mm}-\mathrm{NaHCO}_{3}, 21.58 \mathrm{~mm}$-sodium lactate, $0.5 \mathrm{~mm}$-sodium pyruvate, $4 \mathrm{mg} \mathrm{BSA} / \mathrm{ml}, 50 \mu \mathrm{g}$ streptomycin sulphate $/ \mathrm{ml}$ and $75 \mu \mathrm{g}$ potassium penicillin $\mathrm{G} / \mathrm{ml}$ ) used by Toyoda \& Chang (1974) for fertilization of rat eggs in vitro, except that various hexoses of different concentrations were added for the incubations for capacitation and fertilization.

White rats of the Wistar strain were used. Spermatozoa were obtained from the cauda epididymidis of adult rats 200-300 days old. A small drop of the dense sperm mass was first introduced into $0.5 \mathrm{ml}$ basic medium covered with warm paraffin oil (Nakarai Chemical Co.) in a plastic culture dish (35 $\times 11 \mathrm{~mm}$ : Toyoshima Seisakusho) (Niwa \& Chang, 1973; Toyoda \& Chang, 1974). The paraffin oil was previously equilibrated with $5 \% \mathrm{CO}_{2}$ in air. About $10 \mathrm{~min}$ after preparation of this sperm suspension, $0.04 \mathrm{ml}$ was placed with a micropipette (Eppendorf) in $0.4 \mathrm{ml}$ of the test medium to give the hexose concentrations shown in Tables $1-3$. The diluted sperm suspension $\left(0.3-0.9 \times 10^{6}\right.$ spermatozoa/ml) was preincubated for $5-5.5 \mathrm{~h}$ in a $\mathrm{CO}_{2}$ incubator $\left(5 \% \mathrm{CO}_{2}\right.$ in air at $\left.37^{\circ} \mathrm{C}\right)(\mathrm{Niwa} \&$ Chang, 1974b). 
Immature females aged 21-24 days were induced to superovulate by a s.c. injection of 10 i.u. PMSG (Serotropin: Teikoku-Zoki Co.) $40 \mathrm{~h}$ before an i.p. injection of 10 i.u. hCG (Puberogen: Sankyo Co.). The eggs were obtained in cumulus clots from the ampullar portion of the oviducts 14-15 $\mathrm{h}$ after the injection of hCG and then introduced into the preincubated sperm suspension. After further incubation for $5-5.5 \mathrm{~h}$, the eggs were mounted in toto, stained with $0.25 \%$ lacmoid (Chang, 1952) and examined for evidence of sperm penetration and fertilization. 'Penetrated' eggs were those which had been penetrated by spermatozoa, including those with spermatozoa in the perivitelline space. Eggs with an enlarged sperm head(s) or male pronucleus(ei) in the vitellus were considered to be undergoing fertilization. The proportion of eggs penetrated and with a male pronucleus was used as the criterion for completion of sperm capacitation or time of penetration of eggs because it has been reported that rat eggs penetrated in vitro after insemination with non-capacitated spermatozoa (preincubated for $0 \cdot 5-1 \mathrm{~h}$ ) do not have a male pronucleus at $5-5.5 \mathrm{~h}$ but that almost all eggs $(97 \%)$ have a male pronucleus when capacitated spermatozoa (preincubated for $5-5.5 \mathrm{~h}$ ) and eggs are incubated for 5-5.5 h (Niwa \& Chang, 1974b).

Three experiments were carried out. In Exp. 1, 0, 1.53, 3.06, 6.12 and 9.17 mM-D-glucose were added to the basic medium for sperm preincubation and fertilization of eggs. In Exp. 2, the basic medium was supplemented with D-glucose, D-fructose, D-mannose or D-galactose (all at $6.12 \mathrm{~mm}$ ). In Exp. 3, the independent effects of the different hexoses on sperm capacitation and egg penetration were tested. The medium for preincubation of spermatozoa contained 0 (control) or 3.06 mM-Dglucose, D-fructose, D-mannose or D-galactose. When the eggs were introduced into the sperm suspension, $0.04 \mathrm{ml}$ basic medium containing $36.14 \mathrm{~mm}(66.72 \mathrm{~mm}$ for the controls) hexose was also added, thus giving a final concentration of $5.56 \mathrm{~mm}$-hexose(s) in the fertilization medium.

\begin{abstract}
Results

\section{Experiment 1}

The results show that fertilization of rat eggs does not occur when there was no D-glucose in the medium (Table 1). Very high proportions of the eggs examined were penetrated when D-glucose was present, but the proportion of eggs penetrated and with a male pronucleus was significantly higher in the medium containing $5.56 \mathrm{mM}$-D-glucose.
\end{abstract}

Table 1. Effect of the concentration of D-glucose on fertilization of rat eggs in vitro

\begin{tabular}{cccccc}
\hline $\begin{array}{c}\text { Conc. of } \\
\text { D-glucose } \\
(\mathrm{mM})\end{array}$ & $\begin{array}{c}\text { No. of } \\
\text { eggs } \\
\text { examined }\end{array}$ & $\begin{array}{c}\text { Total } \\
(\%)\end{array}$ & $\begin{array}{c}\text { With sperm. in } \\
\text { perivitelline } \\
\text { space only }\end{array}$ & $\begin{array}{c}\text { With } \\
\text { enlarged } \\
\text { sperm head }\end{array}$ & $\begin{array}{c}\text { With male } \\
\text { pronucleus } \\
(\%)\end{array}$ \\
\hline 0 & 62 & $0(0)$ & 0 & 0 & $0(0)$ \\
1.39 & 65 & $58(89)$ & 21 & 37 & $0(0)$ \\
2.78 & 61 & $61(100)$ & 1 & 12 & $13(21)$ \\
5.56 & 57 & $57(100)$ & 0 & 21 & $45(79)^{*}$ \\
8.34 & 57 & $\dagger 50(88)$ & 0 & $27(54)$
\end{tabular}

Eggs were examined $5-5 \cdot 5 \mathrm{~h}$ after insemination with spermatozoa preincubated for $5-5 \cdot 5 \mathrm{~h}$ in the medium containing D-glucose as indicated.

* Significantly different from the values with other concentrations of D-glucose $\left(P<0 \cdot 01, \chi^{2}\right.$ test $)$.

$\uparrow$ Including 2 eggs penetrated with a sperm tail but there was no sperm head in the vitellus.

\title{
Experiment 2
}

As shown in Table 2, fertilization of rat eggs did not occur when the medium did not contain hexoses or did contain D-fructose. The results with D-galactose were almost as poor, but D-mannose permitted some penetration and fertilization. 
Table 2. Effect of different hexoses on fertilization of rat eggs in vitro

\begin{tabular}{lccc}
\hline & & \multicolumn{2}{c}{ No. of eggs } \\
\cline { 3 - 4 } $\begin{array}{c}\text { Hexose added } \\
\text { to medium }\end{array}$ & $\begin{array}{c}\text { No. of } \\
\text { eggs } \\
\text { examined }\end{array}$ & $\begin{array}{c}\text { Penetrated } \\
(\%)\end{array}$ & $\begin{array}{c}\text { Undergoing } \\
\text { fertilization } \\
(\%)\end{array}$ \\
\hline None & 58 & $0(0)$ & $0(0)$ \\
D-Glucose & 63 & $63(100)$ & $63(100)$ \\
D-Fructose & 60 & $0(0)$ & $0(0)$ \\
D-Mannose & 61 & $36(59)$ & $27(44)$ \\
D-Galactose & 77 & $3(4)$ & $2(3)$ \\
\hline
\end{tabular}

Eggs were examined $5-5.5 \mathrm{~h}$ after insemination with spermatozoa preincubated for $5-5.5 \mathrm{~h}$ in the same medium containing 0 or $5.56 \mathrm{mM}$ hexose.

Table 3. Effects of different hexoses on sperm capacitation and on penetration of rat eggs in vitro

\begin{tabular}{|c|c|c|c|c|c|c|}
\hline \multirow{2}{*}{\multicolumn{2}{|c|}{ Hexoses in medium }} & \multirow{3}{*}{$\begin{array}{l}\text { No. of } \\
\text { eggs } \\
\text { examined } t\end{array}$} & \multicolumn{4}{|c|}{ No. of eggs penetrated } \\
\hline & & & \multirow[b]{2}{*}{$\begin{array}{l}\text { Total } \\
(\%)\end{array}$} & \multirow{2}{*}{$\begin{array}{l}\text { With sperm. in } \\
\text { perivitelline } \\
\text { space only }\end{array}$} & \multirow{2}{*}{$\begin{array}{c}\text { With } \\
\text { enlarged } \\
\text { sperm head }\end{array}$} & \multirow{2}{*}{$\begin{array}{c}\text { With male } \\
\text { pronucleus } \\
(\%)\end{array}$} \\
\hline $\begin{array}{c}\text { For sperm } \\
\text { preincubation* }\end{array}$ & $\stackrel{\text { At }}{\text { insemination } \dagger}$ & & & & & \\
\hline \multirow{4}{*}{ None } & G & 72 & $68(94)$ & 0 & 44 & $24(35)$ \\
\hline & $\mathbf{F}$ & 54 & $0(0)$ & 0 & 0 & $0(0)$ \\
\hline & $\mathbf{M}$ & 88 & $84(95)$ & 2 & 44 & $38(45)$ \\
\hline & $\mathrm{Ga}$ & 76 & $0(0)$ & 0 & 0 & $0(0)$ \\
\hline \multirow[t]{4}{*}{ D-Glucose (G) } & G & 95 & $95(100)$ & 0 & 10 & $85(89)$ \\
\hline & $F$ & 89 & $88(99)$ & 0 & 42 & $46(52)$ \\
\hline & $\mathbf{M}$ & 48 & $48(100)$ & 2 & 5 & $41(85)$ \\
\hline & $\mathrm{Ga}$ & 46 & $46(100)$ & $\mathbf{0}$ & 5 & $41(89)$ \\
\hline \multirow[t]{4}{*}{ D-Fructose (F) } & $\mathrm{G}$ & 114 & $99(87)$ & 13 & 46 & $40(40)$ \\
\hline & $\mathbf{F}$ & 84 & $0(0)$ & 0 & 0 & $0(0)$ \\
\hline & $\mathbf{M}$ & 59 & $56(95)$ & 4 & 25 & $27(48)$ \\
\hline & $\mathrm{Ga}$ & 53 & $0(0)$ & 0 & 0 & $0(0)$ \\
\hline \multirow[t]{4}{*}{ D-Mannose $(\mathrm{M})$} & $\mathrm{G}$ & 64 & $64(100)$ & 0 & 3 & $61(95)$ \\
\hline & $F$ & 60 & $55(92)$ & 5 & 27 & $23(42)$ \\
\hline & $\mathbf{M}$ & 76 & $75(99)$ & 2 & 8 & $65(87)$ \\
\hline & $\mathrm{Ga}$ & 50 & $47(94)$ & 1 & 10 & $36(77)$ \\
\hline \multirow[t]{4}{*}{ D-Galactose (Ga) } & $\mathbf{G}$ & 54 & $54(100)$ & 0 & 7 & $47(87)$ \\
\hline & $\mathbf{F}$ & 69 & $0(0)$ & 0 & 0 & $0(0)$ \\
\hline & $\mathbf{M}$ & 69 & $68(99)$ & 7 & 7 & $54(79)$ \\
\hline & $\mathrm{Ga}$ & 58 & $0(0)$ & 0 & 0 & $0(0)$ \\
\hline
\end{tabular}

* Epididymal spermatozoa were preincubated for 5-5.5 h in medium containing each hexose at a concentration of $2.78 \mathrm{~mm}$ and then eggs in cumulus clots were introduced.

$\dagger$ The final concentration of hexose(s) was $5.56 \mathrm{~mm}$ (see text).

† The eggs were examined 5-5.5 h after insemination.

\section{Experiment 3}

As shown in Table 3, after preincubation of epididymal spermatozoa in medium without hexoses, most of the eggs examined were penetrated but low proportions had a male pronucleus when Dglucose or D-mannose was added at the insemination, but there was no penetration with addition of D-fructose or D-galactose. Very similar results were obtained when spermatozoa were preincubated in medium with $\mathrm{D}$-fructose or D-galactose. Very high proportions of eggs were penetrated when 
spermatozoa were preincubated in medium with D-glucose or D-mannose, whatever the hexose provided at insemination, but the proportions of eggs penetrated and with a male pronucleus were lower when the supplement was D-fructose than one of the other hexoses.

\section{Discussion}

In the present experiments, lactate, pyruvate and bovine serum albumin were always included in the medium but no rat eggs were penetrated when epididymal spermatozoa were preincubated and then inseminated with eggs in the medium without D-glucose. Tsunoda \& Chang (1975) reported that fertilization of rat eggs in vitro could not be achieved in the medium with only glucose as energy source. However, Hoppe (1976) found that capacitation of mouse spermatozoa during a $3 \mathrm{~h}$ preincubation period occurred equally well in the complete medium with glucose, lactate and pyruvate and in medium from which lactate and pyruvate had been omitted. The present results indicate that D-glucose might be one of the most important energy sources for fertilization of rat eggs in vitro. Sperm penetration is possible in media with a wide range $(1.39-8.34 \mathrm{~mm})$ of concentrations of D-glucose and many of these eggs also became fertilized, although the optimal concentration for penetration and development of the male pronucleus appears to be $5.56 \mathrm{~mm}$ (Table 1).

Hoppe (1976) reported that fructose substituted for glucose in a chemically defined medium was not effective for fertilization of mouse eggs in vitro. In the present study with rat eggs, the substitution of D-fructose or D-galactose for D-glucose resulted in very poor fertilization rates $(0$ and $3 \%$, respectively), but D-mannose was effective, although the proportions of eggs penetrated $(59 \%)$ and undergoing fertilization $(44 \%)$ were fairly low when eggs were inseminated with spermatozoa also preincubated in the same medium with D-mannose (Table 2).

It is not possible to preincubate the spermatozoa in hexoses and then inseminate without hexoses present because this would necessitate dilution of the preincubated spermatozoa to remove the hexose in the medium. The capacitation of rat spermatozoa is best achieved when they are preincubated in a diluted $\left(0 \cdot 7-1.2 \times 10^{6}\right.$ spermatozoa $\left./ \mathrm{ml}\right)$ rather than in a concentrated suspension (9.6$14.9 \times 10^{6}$ spermatozoa/ml) (Niwa \& Chang, 1974b), and the optimal sperm concentration for fertilization in vitro of eggs from immature rats is $0 \cdot 16-1.5 \times 10^{6}$ spermatozoa $/ \mathrm{ml}$ (Niwa \& Chang, 1974a). It is therefore difficult to use a more diluted sperm suspension for insemination than that already used for preincubation. The results shown in Table 3 indicate that rat epididymal spermatozoa could be partly capacitated in the medium without hexoses because very high proportions of eggs examined were penetrated and $35-45 \%$ had a male pronucleus when D-glucose or D-mannose was provided at insemination. D-Fructose does not appear to be effective for sperm capacitation because after preincubation of spermatozoa in medium with D-fructose the proportions of eggs penetrated $(87-95 \%)$ and of those with a male pronucleus $(40-48 \%)$ were almost the same as those obtained in the control experiments when D-glucose or D-mannose was provided at insemination. D-Glucose, D-mannose and D-galactose were all equally effective for sperm capacitation. The comparatively low proportions of eggs penetrated and with a male pronucleus when spermatozoa were preincubated in the medium with D-glucose $(52 \%)$ or D-mannose $(42 \%)$ and D-fructose was added at the insemination may have been due to the low concentration $(2.78 \mathrm{~mm})$ of hexoses which are effective for sperm capacitation and for penetration. The lack of penetration of eggs when spermatozoa were preincubated in medium without hexoses, with D-fructose or D-galactose and then D-fructose or D-galactose was added at insemination may indicate that the only hexoses which are effective for sperm penetration in vitro are D-glucose and D-mannose. Thus the independent requirements of Dglucose, D-fructose, D-mannose and D-galactose for sperm capacitation and for penetration of rat eggs in vitro are well demonstrated. The discrepancy (44\% and $96 \%$ ) between the results of Exps 2 and 3 for the proportions of eggs undergoing fertilization when D-mannose was used for preincubation and fertilization requires further study.

Rogers \& Yanagimachi (1975) have reported that medium containing only pyruvate or pyruvate and lactate as energy sources induced the earliest acrosome reaction and that the presence of glucose or other glycolysable sugars in addition to pyruvate and lactate retarded the occurrence of the 
acrosome reaction in guinea-pig spermatozoa. The acrosome reaction of rat spermatozoa is difficult to detect under a light microscope (Austin \& Bishop, 1958), and it was not examined in the present study. However, when D-glucose was absent from the medium, no rat eggs were penetrated in vitro (Tables 1 and 2) and when spermatozoa were preincubated in the medium without D-glucose they could be only partly capacitated (Table 3 ). These facts suggest that D-glucose does not retard, and perhaps improves, the capacitation and/or the acrosome reaction of rat epididymal spermatozoa.

Some of this work was supported by a grant from the Ford Foundation (No. 740-0404). We thank Mr M. Miyake and Mr H. Imai for assistance.

\section{References}

Austin, C.R. \& Bishop, M.W.H. (1958) Role of the rodent acrosome and perforatorium in fertilization. Proc. R. Soc. B 149, 241-248.

Chang, M.C. (1952) Fertilizability of rabbit ova and the effects of temperature in vitro on their subsequent fertilization and activation in vivo. J. exp. Zool. 121, 351-381.

HOPPE, P.C. (1976) Glucose requirement for mouse sperm capacitation in vitro. Biol. Reprod. 15, 39-45.

MaNN, T. (1964) The Biochemistry of Semen and of the Male Reproductive Tract. Methuen, London.

Miyamoto, H. \& Chang, M.C. (1973) The importance of serum albumin and metabolic intermediates for capacitation of spermatozoa and fertilization of mouse eggs in vitro. J. Reprod. Fert. 32, 193-205.

Niwa, K. \& ChaNG, M.C. (1973) Fertilization in vitro of rat eggs as affected by the maturity of the females and the sperm concentration. J. Reprod. Fert. 35, 577580.

Niwa, K. \& Chang, M.C. (1974a) Optimal sperm concentration and minimal number of spermatozoa for fertilization in vitro of rat eggs. J. Reprod. Fert. 40, 471-474.

Niwa, K. \& Chang, M.C. (1974b) Effect of sperm concentration on the capacitation of rat spermatozoa. J. exp. Zool. 189, 353-356.

Rogers, B.J. \& YANAGIMACHI, R. (1975) Retardation of guinea pig sperm acrosome reaction by glucose: the possible importance of pyruvate and lactate metabolism in capacitation and the acrosome reaction. Biol. Reprod. 13, 568-575.

Toyoda, Y. \& Chang, M.C. (1974) Fertilization of rat eggs in vitro by epididymal spermatozoa and the development of eggs following transfer. $J$. Reprod. Fert. 36, 9-22.

TsunODA, Y. \& CHANG, M.C. (1975) In vitro fertilization of rat and mouse eggs by ejaculated sperm and the effect of energy sources on in vitro fertilization of rat eggs. J. exp. Zool. 193, 79-86.

Received 6 October 1977 